\title{
Effects of size and shape on electronic states of quantum dots
}

\author{
Chun Yong Ngo - Soon Fatt Yoon - Weijun J. Fan • \\ Soo Jin Chua
}

Published online: 28 September 2007

(C) Springer Science+Business Media, LLC. 2007

\section{Erratum to: Opt Quant Electron (2007) 38: 981-991 DOI 10.1007/s11082-006-9027-7}

Following an inquiry by the Editors of the Journal and, subsequently, by Nanyang Technical University and the authors, this paper will formally be retracted from Optical and Quantum Electronics.

It was an error of judgement on the authors' part that the above Optical and Quantum Electronics paper, containing results partially extracted from the Physical Review B paper (Vol. 74, Article No. 245331, 2006) and originally intended for a Conference (Numerical Simulation on Optoelectronic Devices, 11-14 September 2006, Singapore) presentation, became a submission to your journal. The authors did not mean to mislead the journal or the scientific community. The authors apologize for this error.

The online version of the original article can be found under doi:10.1007/s11082-006-9027-7.

C. Y. Ngo $(\varangle)$ · S. F. Yoon · W. J. Fan

School of Electrical and Electronic Engineering (Block S1), Nanyang Technological University, Nanyang Avenue, Singapore 639798, Singapore

e-mail: ngoc0003@ntu.edu.sg

\section{S. J. Chua}

Institute of Materials Research and Engineering, Faculty of Engineering, 3 Research Link, Singapore 117602, Singapore 